\title{
VALIDASI KUAT TEKAN DAN KUAT LENTUR BETON NORMAL TERHADAP KUAT TEKAN DAN KUAT LENTUR BETON DENGAN PENAMBAHAN SERBUK KAYU JATI DAN SERBUK KAYU KELAPA
}

\author{
Oleh: Erlina ${ }^{1}$ \\ E-mail: erlinahakuan@gmail.com
}

\begin{abstract}
ABSTRAK: Pembangunan yang berwawasan lingkungan merupakan wacana baru yang harus dikembangkan baik dalam penyelenggaraan maupun pengelolaannya. Pengembangan bahan bangunan dari limbah selain dapat menunjang kebutuhan pembangunan juga dapat memecahkan masalah lingkungan yang selanjutnya produk ini dapat dikategorikan sebagai bahan bangunan ekologis.
\end{abstract}

Penelitian ini bertujuan untuk mengetahui pengaruh penambahan limbah serbuk kayu jati dan serbuk kayu kelapa terhadap kuat tekan beton dan kuat lentur beton. Penelitian dilakukan dengan membuat benda uji berupa silinder beton untuk uji kuat tekan dan balok beton untuk uji kuat lentur dengan variasi penambahan serbuk kayu mulai dari 0\%, 25\%, 50\%, 75\% dan $100 \%$.

Untuk persiapan dan pembuatan benda uji dilakukan di Laboratorium Bahan FT UCY, pengujian kuat tekan dilakukan di Laboratorium Bahan FT Universitas Atma Jaya Yogyakarta sedangkan pengujian kuat lenturnya dilakukan di Laboratorium Bahan FT UCY. Pembuatan benda uji dengan menggunakan metode campuran beton pada "Road Note No. 4".

Hasil penelitian menunjukkan bahwa pasir mempunyai modulus halus butir 2,835, berat jenis (SSD) sebesar 2,642, kadar serapan air sebesar 4,95\% dan kandungan lumpur sebesar 2,95\%. Agregat kasar mempunyai modulus halus butiran 7,02, berat jenis (SSD) 2,623 dan serapan air sebesar 2,674\%. Kayu jati mempunyai berat jenis sebesar 0,67 dan kayu kelapa mempunyai berat jenis sebesar 0,71. Beton dengan penambahan serbuk kayu jati mempunyai serapan air yang lebih besar dibandingkan dengan beton dengan penambahan serbuk kayu kelapa dimana serapan air pada beton dengan penambahan serbuk kayu jati berkisar antara 12,45-41,65\% dan pada penambahan serbuk kayu kelapa sebesar 9,41$36,28 \%$. Beton dengan penambahan serbuk kayu jati mempunyai berat jenis, kuat tekan, modulus elastisitas dan kuat lentur yang lebih kecil dibandingkan dengan beton dengan penambahan serbuk kayu kelapa. Berat jenis beton dengan penambahan serbuk kayu jati 25-100\% berkisar antara 1837,092-1225,839 kg/m3 dan pada kayu kelapa antara 2047,439$1237,370 \mathrm{~kg} / \mathrm{m} 3$. Kuat tekan beton dengan penambahan serbuk kayu jati $25-100 \%$ berkisar antara 8,479-0,110 MPa dan pada kayu kelapa antara 13,670-0,145 MPa. Kuat lentur beton dengan penambahan serbuk kayu jati 25-100\% berkisar antara 1,797-0,470 MPa dan pada kayu kelapa antara 1,948-0,489 MPaPergerakan yang berasal dari Perumnas Condongcatur Kecamatan Depok Kabupaten Sleman Propinsi Daerah Istimewa Yogyakarta, dipengaruhi oleh Ukuran Rumah Tangga, Pemilkan Kendaraan, dan Pendapatan.

Kata kunci: Beton, Kuat Lentur, Kuat Tekan, Modulus Elastisitas, Serbuk Kayu Jati, Serbuk Kayu Kelapa

1) adalah staf pengajar Program Studi Teknik Sipil Universitas Cokroaminoto Yogyakarta 


\section{PENDAHULUAN}

\subsection{Latar Belakang}

Dalam upaya memenuhi tuntutan hidup dan meningkatkan kesejahteraan masyarakat, perlu dilaksanakan pembangunan. Kegiatan pembangunan yang selama ini dilaksanakan telah membawa kemajuan yang pesat diberbagai bidang. Pembangunan yang berwawasan lingkungan merupakan wacana baru yang harus dikembangkan baik dalam penyelenggaraan maupun pengelolaannya.

Manusia dan pembangunan merupakan dua hal yang tidak terpisahkan karena pembangunan merupakan bagian dari kebutuhan hidup dalam meningkatkan kesejahteraannya. Selain produk bahan dan komponen bangunan manusia juga telah mengembangkan beberapa produk lain baik dibidang energi maupun kebutuhan dasar lainnya untuk memenuhi kebutuhan hidup. Pengembangan ini dalam prosesnya menghasilkan bahan sisa atau limbah. Limbah dari berbagai proses tersebut memerlukan pengelolaan yang lebih baik dengan memanfaatkan kembali secara optimal, tepat dan bijaksana agar tidak menimbulkan dampak negatif bagi lingkungan. Salah satu upaya yang dapat dilakukan adalah dengan meningkatkan kegunaannya sebagai bahan bangunan. Pengembangan bahan bangunan dari limbah ini selain dapat menunjang kebutuhan pembangunan juga dapat memecahkan masalah lingkungan yang selanjutnya produk ini dapat dikategorikan sebagai bahan bangunan ekologis. Bahan bangunan ekologis yang dimaksudkan adalah bahan bangunan yang dibentuk dari sisa atau limbah industri melalui proses yang ramah lingkungan serta aman terhadap kesehatan baik saat diterapkan maupun pemanfaatan bangunan.

\subsection{Manfaat Penelitian}

Manfaat penelitian ini adalah untuk mengetahui pengaruh penggunaan limbah serbuk penggergajian pada mortar semen sebagai bahan pengganti agregat dan memberikan perkembangan masalah beton dan mortar dalam dunia keteknik sipilan.

\subsection{Tujuan Penelitian}

Tujuan penelitian ini adalah untuk mengetahui sifat-sifat fisik beton yang menggunakan campuran antara serbuk kayu jati dengan mortar semen dan serbuk kayu kelapa dengan mortar semen. Selain itu untuk mengetahui pengaruh penambahan limbah serbuk kayu jati dan serbuk kayu kelapa terhadap kuat tekan beton dan pengaruh penambahan limbah serbuk kayu jati dan serbuk kayu kelapa terhadap kuat lentur beton.

\subsection{Batasan Penelitian}

Agregat yang digunakan berasal dari Sungai Gendol Yogyakarta dengan butiran maksimal $20 \mathrm{~mm}$, Perbandingan volume antara jumlah pasir dan serbuk kayu bervariasi mulai dari0\%, 25\%, 50\%, 75\% dan 100\%, Serbuk kayu jati yang digunakan adalah limbah penggergajian kayu salah satu warga dan limbah penggergajian kayu kelapa dari industri penggergajian kayu kelapa di Taji, Prambanan, Klaten.

\section{TINJAUAN PUSTAKA}

\subsection{Pengertian Umum}

Beton adalah bahan bangunan yang terdiri dari campuran semen, agregat

2 Validasi Kuat Tekan dan Kuat Lentur Beton Normal Terhadap Kuat Tekan dan Kuat Lentur Beton dengan Penambahan Serbuk Kayu Jati dan Serbuk Kayu Kelapa (Erlina) 
dan air serta jika perlu ditambah dengan bahan tambah yang sangat bervariasi mulai dari bahan kimia tambahan, serat sampai dengan bahan buangan non kimia seperti limbah beton, batu pecah dengan perbandingan tertentu, campuran tersebut bila dituang dalam cetakan kemudian dibiarkan akan mengeras seperti batuan. Dalam SK SNI : T-15-1991-03 beton didefinisikan sebagai campuran antara semen portland atau semen hidraulik yang lain, agregat halus, agregat kasar dan air dengan atau tanpa bahan tambah membentuk massa padat. Secara umum beton merupakan hasil reaksi semen hidraulik dengan air. Tetapi belakangan ini didefinisikan semakin luas yaitu beton yang terbuat dari berbagai tipe semen dan juga bahan pozzolan, abu terbang, terak tanur tinggi, sulfur polimer serat dan lain-lain (Neville dan Brooks, 1987). Berdasarkan berat beton dan jenis pemakaiannya beton dikelompokkan menjadi tiga kelompok seperti dalam tabel 1 (Tjokrodimuljo, 1996).

Tabel 1 Jenis-jenis beton berdasarkan berat beton dan agregat penyusunnya

\begin{tabular}{|l|c|l|}
\hline \multicolumn{1}{|c|}{ Jenis Beton } & Berat beton $\left(\mathrm{kg} / \mathrm{m}^{3}\right)$ & \multicolumn{1}{|c|}{ Pemakaian } \\
\hline Beton sangat ringan & $<1000$ & Non struktur \\
\hline Beton ringan & $1000-2000$ & Struktur ringan \\
\hline Beton normal (biasa) & $2300-2500$ & Struktur \\
\hline Beton berat & $>3000$ & Perisai sinar $X$ \\
\hline
\end{tabular}

\subsection{Bahan Penyusun Beton}

Beton diperoleh dengan mencampurkan semen portland, air dan agregat atau kadang-kadang bahan tambah pada perbandingan tertentu. Agregat merupakan bahan pengisi beton. Adapun semen dan air akan selalu bereaksi melalui proses hidrasi membentuk pasta semen yang akan mengeras dan merekatkan butiran agregat. Campuran tersebut bila dituang dalam cetakan dan dibiarkan akan mengeras seperti batuan. Pengerasan terjadi akibat dari peristiwa reaksi kimia antara air dan semen yang berlangsung selama waktu yang panjang dan akibatnya campuran ini selalu bertambah keras sesuai dengan bertambahnya umur. Kekuatan, keawetan dan sifat beton yang lain tergantung pada sifat-sifat bahan dasar beton tersebut, nilai perbandingan bahannya,cara pengadukan, cara pengerjaan selama penuangan adukan beton, cara pemadatan serta cara perawatan selama pengerasan (Tjokrodimuljo, 1996).

Semen portland adalah semen hidrolis yang dihasilkan dengan cara menghasilkan klinker yang terutama terdiri dari silikat-silikat kalsium yang bersifat hidrolis dengan gipsum sebagai bahan tambah (PUBI, 1982). Semen yang digunakan untuk bahan beton adalah semen portland atau semen portlandpozzolan, berupa semen hidrolik yang berfungsi sebagai bahan perekat bahan susun beton. Jenis semen tersebut memerlukan air guna berlangsungnya proses hidrasi. Pada proses hidrasi semen mengeras dan mengikat bahan susun beton membentuk massa padat (Dipohusodo, 1996).

Air merupakan bahan dasar pembuatan beton yang penting namun murah harganya. Air diperlukan pada pembuatan semen yang berpengaruh pada sifat dapat dikerjakan (workability) dari adukan beton, kekuatan, susut dan keawetan betonnya. Tujuan utama penggunaan air adalah agar terjadi hidrasi yaitu reaksi kimia antara semen dan air yang menyebabkan campuran menjadi keras setelah lewat beberapa waktu tertentu. Pada dasarnya yang dibutuhkan untuk bereaksi dengan semen adalah $25 \%$ dari berat semen. Namun dalam kenyataannya nilai faktor air semen yang dipakai sulit jika kurang dari 0,350.

Validasi Kuat Tekan dan Kuat Lentur Beton Normal Terhadap Kuat Tekan dan Kuat Lentur Beton dengan Penambahan Serbuk Kayu Jati dan Serbuk Kayu Kelapa (Erlina) 
Campuran beton pada umumnya menggunakan agregat sebagai bahan pengisi dengan volume $60 \%$ sampai $70 \%$ dari volume totalnya. Walaupun hanya sebagai bahan pengisi, akan tetapi agregat berpengaruh terhadap sifat-sifat dan kualitas beton sehingga pemilihan agregat merupakan suatu bagian yang penting dalam pembuatan beton. Agregat yang ada relatif murah harganya maka dari itu dianjurkan untuk menggunakan bahan ini sebanyak mungkin agar beton yang dihasilkan ekonomis. Disamping itu pemakaian banyak agregat juga dapat mengurangi koefisien ekspansi panas (Tjokrodimuljo, 1992). Agregat adalah butiran mineral alami yang berfungsi sebagai bahan pengisi dalam campuran mortar atau beton. Agregat yang paling sering digunakan untuk beton bangunan adalah pasir dan kerikil karena pertimbangan ekonomis dan kemudahan pengerjaannya. Sifat yang paling penting dari suatu agregat adalah kekuatan hancur dan ketahanan terhadap benturan yang dapat mempengaruhi ikatannya dengan pasta semen, porositas dan karakteristik penyerapan air yang mempengaruhi daya tahan terhadap reaksi kimia dan penyusutan (Murdock, L.J., 1986).

\subsection{Serbuk Kayu}

Kayu jati memiliki nama botani Tectona Grandis L.F. Di Indonesia kayu jati memiliki berbagai jenis nama daerah yaitu delek, dodolan, jate, jatih, jatos, kioti, kalidawa dan lain-lain. Berdasarkan PPKI 1961 kayu jati termasuk kayu dengan tingkat pemakaian I, kekuatan II dan tingkat keawetan I. Kelapa (Cocos nucifera L) termasuk suku Arecaceae disebut juga pohon nyiur. Kelapa termasuk tanaman monokotil (berbijih tunggal), tidak memiliki kambium tetapi memiliki sebuah titik tumbuh yang letaknya disebelah atas sehingga tumbuhnya selalu mengarah ke atas dan umumnya tidak bercabang.

Berat jenis terbesar kayu kelapa terdapat pada bagian pangkal tepi dan berat jenis terkecil terdapat pada bagian ujung dalam (Morisco, dkk, 1998 dalam Ali Awaludin, dkk, 2002). Untuk serbuk kayu kelapa pada dasarnya merupakan partikelpartikel kayu yang terurai dan jika disatukan kembali maka sifat-sifatnya hampir sama dengan kayu kelapa dalam keadaan utuh, baik untuk sifat-sifat fisik kayu kelapa, sifat-sifat mekanik maupun sifat-sifat kimianya (Dumanau W, 1992 dalam Supriyanto, 1998).

\section{LANDASAN TEORI}

\subsection{Kuat Tekan}

Sifat yang paling penting dari beton adalah kuat tekan. Kuat tekan biasanya berhubungan dengan sifat-sifat lain, maksudnya bila kuat desaknya tinggi sifatsifatnya lain juga (Tjokrodimulyo, 1992). Kekuatan tekan beton dengan benda uji silinder berdiameter $150 \mathrm{~mm}$ dan panjang $300 \mathrm{~mm}$ didasarkan atas kekuatan beton umur 28 hari. Faktor-faktor yang mempengaruhi kuat tekan beton adalah sebagai berikut : faktor air semen, umur beton, jenis semen, jumlah semen dan sifat agregat. Nilai kuat tekan beton dinyatakan dalam satuan $\mathrm{MPa}$ atau $\mathrm{kg} / \mathrm{m} 2$ dapat ditulis

$4 \quad$ Validasi Kuat Tekan dan Kuat Lentur Beton Normal Terhadap Kuat Tekan dan Kuat Lentur Beton dengan Penambahan Serbuk Kayu Jati dan Serbuk Kayu Kelapa (Erlina) 
dengan rumus sebagai berikut :

$F^{\prime} C=P / A$

Dengan f'c adalah kuat tekan / kuat desak $\left(\mathrm{kg} / \mathrm{cm}^{2}\right)$, P adalah beban maksimum $(\mathrm{kg})$, dan A adalah luas tampang $\left(\mathrm{cm}^{2}\right)$.

\subsection{Modulus Elastisitas Beton}

Modulus Elastisitas beton merupakan nilai banding kuat tekan f'c dan regangan $(\varepsilon)$. Untuk mengetahui nilai tersebut harus dilakukan pengujian teganganregangan. Pada pengujian tersebut akan diperoleh grafik hubungan teganganregangan yang bentuknya hampir linier pada pembebanan awal hingga batas elastis, kemudian berbentuk busur pada kondisi plastis hingga kuat batas telah dicapai dan kemudian kuat tekan akan menurun hingga regangan maksimum (pecah). Untuk menghitung modulus elastisitas menggunakan rumus sebagai berikut :

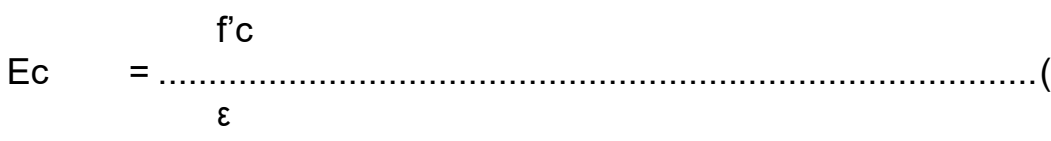

Dengan Ec adalah modulus elastisitas beton (MPa), f'c adalah kuat tekan beton (MPa), dan $\varepsilon$ adalah regangan beton.

\subsection{Kuat Lentur Beton}

Kuat lentur merupakan salah satu dari sifat penting beton. Kuat lentur terbentuk akibat interaksi antara unsur-unsur pembentuknya yaitu semen, pasir, kerikil dan air. Penambahan kekuatan ini dipengaruhi oleh beberapa faktor seperti bahan dasar, proses pengolahan dan perawatan. Salah satu cara menaksir kekuatan lentur beton adalah dengan tes lentur (kuat lentur). Benda uji adalah berupa balok berukuran panjang $60 \mathrm{~cm}$, lebar $15 \mathrm{~cm}$ dan tinggi $15 \mathrm{~cm}$. Benda uji diisi dengan adukan beton masing-masingdengan dua lapisan yang sama dimana setiap lapisan mendapatkan 60 kali rojokan, sesuai yang disyaratkan pada silinder yang tertekan. Balok beton dirawat sesuai dengan pedoman dan diuji kekuatannya. (Aman Subakti, 1994).

\section{CARA PENELITIAN}

Penelitian dilakukan dengan membuat benda uji berupa silinder beton dan balok. Persiapan, pembuatan dan pengujian kuat lentur dilakukan di Laboratorium Bahan FT UCY. Pemeriksaan material meliputi pemeriksaan air dan semen secara visual analisa saringan butir halus (pasir) dan kasar (kerikil), pemeriksaan kandungan lumpur agregat, dan pemeriksaan berat jenis. Perhitungan campuran adukan beton dengan perencanaan campuran beton memahami metode "Road Note". Pengujian dilakukan setelah benda uji mencapai umur 28 hari yang meliputi pengujian kuat tekan, modulus elastisitas, kuatlentur dan resapan air.

Hasil pengujian yang didapatkan kemudian dilakukan analisa dan perhitunganperhitungan lebih lanjut untuk mengetahui perbandingan kuat desak/tekan dan kuat lentur beton dari serbuk kayu jati dan kelapa yang disajikan dalam bentuk tabulasi dan diagram.

\section{HASIL PENELITIAN DAN PEMBAHASAN}

\subsection{Pemeriksaan Bahan Susun}

Pada penelitian ini air dan semen hanya dilakukan pemeriksaan secara visual

Validasi Kuat Tekan dan Kuat Lentur Beton Normal Terhadap Kuat Tekan dan Kuat Lentur Beton dengan Penambahan Serbuk Kayu Jati dan Serbuk Kayu Kelapa (Erlina) 
saja. Berat jenis standar untuk air adalah $1 \mathrm{gram} / \mathrm{cm} 3$ dan untuk semen adalah 3,15 gram/cm3. Pemeriksaan agregat halus menghasilkan data modulus halus butir pada agregat halus adalah 2,835, berat jenis jenuh kering muka (SSD) sebesar 2,642 dan kadar serapan air sebesar 4,95\% sedangkan kandungan lumpur dalam pasir sebesar $2,95 \%$. Pemeriksaan agregat kasar menghasilkan data modulus halus butiran agregat kasar (split) sebesar 7,02. Berat jenis (SSD) 2,623 dan serapan air sebesar 2,674\%. Hasil pemeriksaan terhadap serbuk kayu menghasilkan data kayu jati mempunyai berat jenis sebesar 0,67 sedangkan kayu kelapa mempunyai berat jenis sebesar 0,71.

\subsection{Hasil Pengujian Slump}

Tabel 2 Hasil pengujian slump beton dengan serbuk kayu jati

\begin{tabular}{|c|c|c|c|}
\hline Tipe Beton & Kadar Serbuk Kayu Jati & fas & nilai slump \\
\hline BN & 0 & 0,48 & $\pm 4,5$ \\
\hline BJ -25 & 25 & 0,48 & $\pm 3,0$ \\
\hline BJ -50 & 50 & 0,48 & $\pm 2,5$ \\
\hline BJ -75 & 75 & 0,48 & $\pm 1,0$ \\
\hline BJ -100 & 100 & 0,48 & $\pm 1,0$ \\
\hline
\end{tabular}

Tabel 3 Hasil pengujian slump beton dengan serbuk kayu kelapa

\begin{tabular}{|c|c|c|c|}
\hline Tipe Beton & Kadar Serbuk Kayu Kelapa & fas & nilai slump \\
\hline BN & 0 & 0,48 & $\pm 4,5$ \\
\hline BK -25 & 25 & 0,48 & $\pm 3,0$ \\
\hline BK -50 & 50 & 0,48 & $\pm 2,0$ \\
\hline BK -75 & 75 & 0,48 & $\pm 1,5$ \\
\hline BK -100 & 100 & 0,48 & $\pm 1,0$ \\
\hline
\end{tabular}

\subsection{Penyerapan Air}

Penyerapan air pada beton menunjukkan tingkat porositas atau pori dalam beton. Umumnya kekuatan beton dipengaruhi secara linier oleh tingkat besarnya porositas beton. Data penyerapan air pada beton yang dihasilkan disajikan pada grafik dibawah ini :

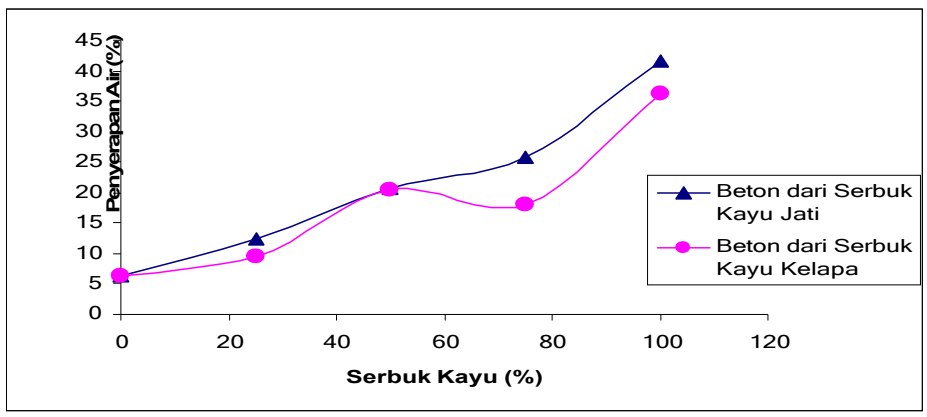

Gambar 1 Penyerapan air

Dari gambar di atas menunjukkan beton yang diberi serbuk kayu kelapa

6 Validasi Kuat Tekan dan Kuat Lentur Beton Normal Terhadap Kuat Tekan dan Kuat Lentur Beton dengan Penambahan Serbuk Kayu Jati dan Serbuk Kayu Kelapa (Erlina) 
mempunyai porositas atau penyerapan air yang makin meningkat drastis dibanding beton normal atau yang tidak diberi sebuk, baik serbuk kelapa maupun serbuk jati.

\subsection{Berat Jenis Beton}

Hubungan berat jenis beton hasil pengujian dan persentase penambahan serbuk kayu disajikan pada grafik dibawah ini :

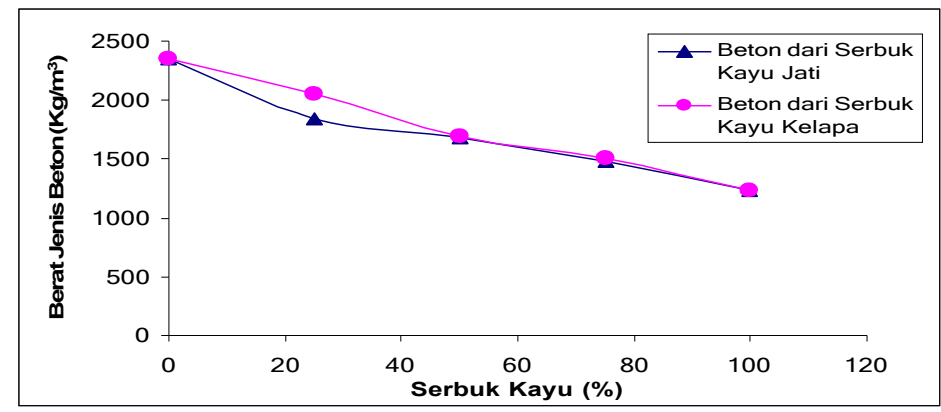

\section{Gambar 2 Berat jenis}

beton

Dari gambar di atas menunjukkan penambahan serbuk kayu kelapa dalam adukan beton berpengaruh terhadap berat jenis beton yang makin menurun seiring dengan penambahan serbuk.

\subsection{Kuat Tekan Beton}

Hubungan kuat tekan dan persentase penambahan serbuk kayu disajikan padagrafik dibawah ini :

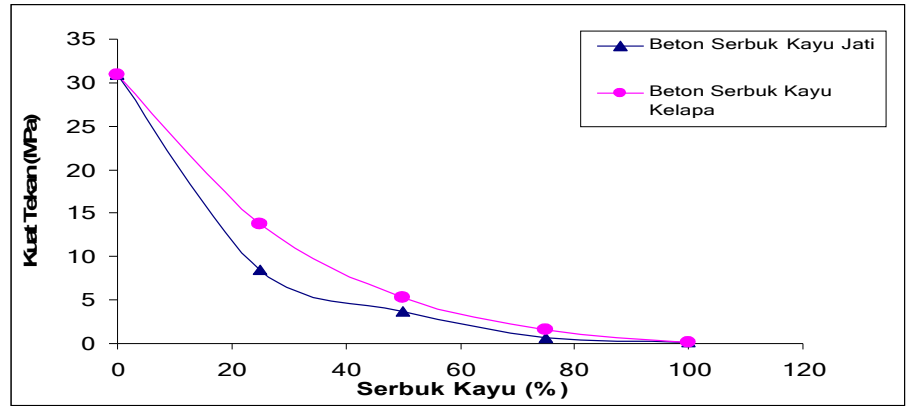

Gambar 3 Kuat tekan

beton

Dari gambar di atas menunjukkan penambahan serbuk kayu kelapa dalam adukanbeton berpengaruh terhadap kuat tekan beton yang makin menurun drastis. 


\subsection{Modulus Elastisitas Beton}

Modulus elastis merupakan indikator kekuatan beton. Dalam penelitian ini tampakmodulus elastis makin menurun setelah diberi bahan tambah serbuk kayu jati maupun serbuk kayu kelapa. Modulus elastisitas beton yang dihasilkan disajikan pada grafik dibawah ini :

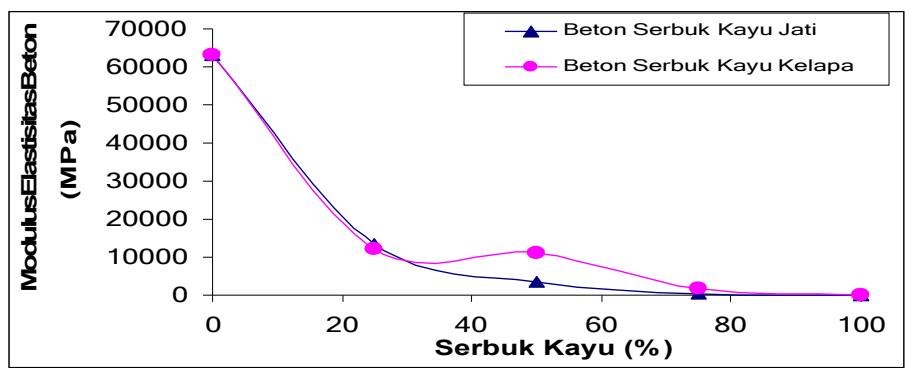

\section{Gambar 4 Modulus elastisitas beton}

\subsection{Kuat Lentur Beton}

Kuat lentur beton untuk tiap variasi penambahan serbuk dapat dilihat pada grafik dibawah ini :

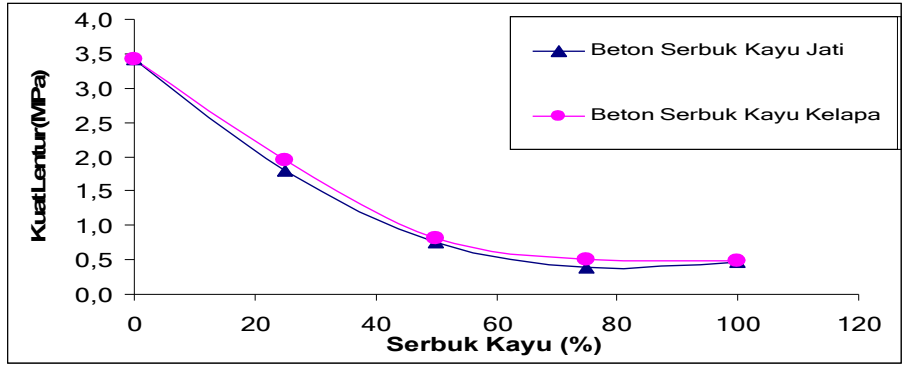

\section{Gambar 5 Kuat lentur beton}

\subsection{Hubungan Kuat Lentur dan Kuat Tekan Beton}

Kuat lentur beton merupakan spesifikasi yang melemahkan sedangkan kuat tekan beton merupakan keutamaannya. Berbagai upaya meningkatkan kedua sifat mekanistersebut telah dilakukan dan dalam penelitian ini penambahan serbuk kayu ternyata justru menurunkan kuat lentur dibanding beton normal tanpa bahan serbuk. Demikian pula terhadap kuat beton ternyata makin menurun. Kondisi ini dapat dipahami mengingat serbuk kayu merupakan bahan organik yang secara mekanis kekuatannya tidak menguntungkan untuk bahan campuran beton. 
Kuat lentur hasil korelasi kuat tekan dan kuat lentur hasil pengujian disajikan pada tabel dibawah ini :

Tabel 4 Korelasi kuat tekan dan kuat lentur

\begin{tabular}{|c|c|c|c|c|c|c|}
\hline \multirow{2}{*}{$\begin{array}{c}\text { Serbuk } \\
\text { Kayu } \\
(\%)\end{array}$} & $\begin{array}{c}\text { Kuat Tekan } \\
\text { Beton }\left(f^{\prime} c\right) \\
(\mathrm{MPa})\end{array}$ & $\begin{array}{c}\text { Kuat Lentur } \\
\text { Korelasi } \\
\left(0,57 \sqrt{ } \mathrm{f}^{\prime} \mathrm{c}\right)(\mathrm{Mpa})\end{array}$ & $\begin{array}{c}\text { Kuat lentur (FIt) } \\
(\mathrm{MPa})\end{array}$ & $\begin{array}{c}\text { Kuat Tekan } \\
\text { Beton }\left(\mathrm{f}^{\prime} \mathrm{c}\right) \\
(\mathrm{MPa})\end{array}$ & $\begin{array}{c}\text { Kuat Lentur } \\
\text { Korelasi } \\
\left(0,57 \sqrt{ } \mathrm{f}^{\prime} \mathrm{c}\right)(\mathrm{Mpa})\end{array}$ & $\begin{array}{c}\text { Kuat lentur } \\
(\mathrm{FIt})(\mathrm{MPa})\end{array}$ \\
\hline 0 & 30,909 & 3,169 & 3,422 & 30,909 & 3,619 & 3,422 \\
\hline 25 & 8,479 & 1,660 & 1,797 & 13,670 & 2,108 & 1,948 \\
\hline 50 & 3,647 & 1,089 & 0,757 & 5,226 & 1,303 & 0,810 \\
\hline 75 & 0,645 & 0,457 & 0,377 & 1,569 & 0,714 & 0,505 \\
\hline 100 & 0,110 & 0,188 & 0,470 & 0,145 & 0,216 & 0,489 \\
\hline
\end{tabular}

\section{KESIMPULAN DAN SARAN}

\subsection{Kesimpulan}

Dari pembahasan sebelumnya, maka dapat diambil kesimpulan sebagai berikut :

1. Agregat halus berupa pasir yang berasal dari Kali Gendol Yogyakarta, mempunyai berat jenis 2,642 $\mathrm{gr} / \mathrm{cm} 3$, serapan air 4,95\% serta MHB 2,835 yang semuanya masih memenuhi syarat sebagai bahan susun.

2. Agregat kasar berupa batu pecah yang berasal dari Clereng, mempunyai berat jenis $2,623 \mathrm{gr} / \mathrm{cm} 3$, serapan air $2,674 \%$ serta MHB 7,96 yang semuanya masih memenuhi syarat sebagai bahan susun.

3. Beton dengan penambahan baik serbuk kayu jati maupun serbuk kayu kelapa mempunyai serapan air yang lebih besar jika dibandingkan dengan beton normal dimana beton dengan penambahan baik serbuk kayu jati mempunyai serapan air sebesar $12,45-41,65 \%$ dan serbuk kayu kelapa sebesar 9,41-36,28\% sedangkan beton normal sebesar $6,24 \%$.

4. Beton dengan penambahan serbuk kayu kelapa mempunyai berat jenis yang lebih besar dibandingkan dengan beton dengan penambahan serbuk kayu jati dimana beton dengan penambahan serbuk kayu kelapa pada variasi $25-100 \%$ mempunyai berat jenis antara $2047,439-1237,370 \mathrm{~kg} / \mathrm{m}^{3}$ sedangkan pada penambahan serbuk kayu jati berkisar antara $1837,092-1225,839 \mathrm{~kg} / \mathrm{m}^{3}$.

5. Beton dengan penambahan serbuk kayu kelapa mempunyai kuat tekan yang lebih besar dibandingkan dengan beton dengan penambahan serbuk kayu jati dimana beton dengan penambahan serbuk kayu kelapa pada variasi $25-100 \%$ mempunyai kuat tekan antara 13,670-0,145 MPa sedangkan pada penambahan serbuk kayu jati antara 8,479-0,110 MPa.

6. Beton dengan penambahan serbuk kayu kelapa mempunyai kuat lentur yang lebih besar dibandingkan dengan beton dengan penambahan serbuk kayu jati dimana beton dengan penambahan serbuk kayu kelapa pada variasi $25-100 \%$ mempunyai kuat lentur antara 1,948-0,489 MPa sedangkan pada penambahan serbuk kayu jati antara 1,797-0,470 MPa.

\subsection{Saran-saran.}

Dalam penelitian pengembangan penambahan serbuk kayu perlu dicoba bebrapa alternatif supaya unsur-unsur yang ada dalam serbuk dapat mendukung perbaikan sifat mekanis campuran beton, misalnya dibakar dan diambil abunya. Cara ini juga dapat mengunrangi susutan campuran beton. Selain itu perlu dipikirkan alternatif material kayunya yang memang mengandung banyak unsur pendukung kekuatan beton seperti silika, pozzolan, dan sebaginya. 


\section{DAFTAR PUSTAKA}

Anonim, 1982, Peraturan Umum Bahan Bangunan Indonesia (PUBI), Penerbit Direktorat Penyelidikan Masalah Bangunan DPU, Bandung,

Anonim, 1971, Peraturan Beton Bertulang Indonesia (PBI), Direktorat Penyelidikan Masalah Bangunan DPU, Bandung,

Awaludin A, 2002, Penggunaan Komposit Glugu Bangkirai pada Struktur Truss, FT, UGM, Yogyakarta.

Christanto Y, 2003, Studi Eksperimental Pengaruh Penambahan Serbuk Sisa Penggergajian Kayu pada Kuat Lentur Balok Beton Mutu f'c $=25 \mathrm{MPa}$, Unika Parahyangan, Bandung.

Dipohusodo I, 1996, Standar Beton Bertulang, Penerbit PT. Gramedia Pustaka Utama DPU, Jakarta.

Murdock L.J, 1986, Bahan dan Praktek Beton, Erlangga, Jakarta.

Neville, A.M. and Brooks, J.J., 1987, Concrete Technology, First Edition, Longman Scientific \& Technical, England

Setyawan Supriyanto, 1998, Tinjauan Sifat-sifat Bata Beton Serat dari Serbuk Penggergajian Kayu Kelapa, Tugas Akhir, Jurusan Teknik Sipil, Fakultas TeknikSipil, Universitas Gadjah Mada, Yogyakarta

Susanto G, 2003, Studi Eksperimental Pengaruh Penambahan Serbuk Sisa Penggergajian Kayu pada Kuat Tekan Beton dengan Benda Uji Silinder dan Kuat Lentur Beton dengan Plat Mutu f'c $=25 \mathrm{MPa}$, Unika Parahyangan, Bandung.

Subakti A, 1994, Teknologi Beton dan Praktek, Laboratorium Jurusan Teknik Sipil, Fakultas Teknik Sipil ITS, Surabaya.

Tjokrodimuljo K, 1992, Buku Ajar Bangunan, Jurusan Teknik Sipil, Fakultas Teknik Sipil, Universitas Gadjah Mada, Yogyakarta.

Tjokrodimuljo K, 1996, Teknologi Beton, Penerbit Natiri, Yogyakarta.

10 Validasi Kuat Tekan dan Kuat Lentur Beton Normal Terhadap Kuat Tekan dan Kuat Lentur Beton dengan Penambahan Serbuk Kayu Jati dan Serbuk Kayu Kelapa (Erlina) 